This PDF is a selection from a published volume from the National Bureau of Economic Research

Volume Title: The Rate and Direction of Inventive Activity Revisited

Volume Author/Editor: Josh Lerner and Scott Stern, editors

Volume Publisher: University of Chicago Press

Volume ISBN: 0-226-47303-1; 978-0-226-47303-1 (cloth)

Volume URL: http://www.nber.org/books/lern11-1

Conference Date: September 30 - October 2, 2010

Publication Date: March 2012

Chapter Title: Some Features of Research by Economists on Technological Change Foreshadowed by The Rate and Direction of Inventive Activity

Chapter Authors: Richard R. Nelson

Chapter URL: http://www.nber.org/chapters/c12346

Chapter pages in book: (p. 35 - 41) 


\section{Some Features of Research by Economists on Technological Change Foreshadowed by The Rate and Direction of Inventive Activity}

Richard R. Nelson

The community of scholars studying technological change now draws from many disciplines. However, almost all of those participating at the 2010 National Bureau of Economic Research (NBER) conference whose proceedings are presented in this volume were economists by training. My observations here are mostly about economists who have been studying technological change. The basic points I want to make are first, that one can see foreshadowed in the papers presented and discussed at the old Conference on The Rate and Direction of Inventive Activity that this conference commemorates many of the directions and characteristics of the research on invention, and technological advance more generally, that has been done by economists since that time. And second, one can also see some of the difficulties and tensions that have marked this field in economics.

The essays by economists at the old conference are nearly unanimous in proposing the usefulness of the broad perspective provided by traditional economic analysis for research on inventive activity. They argued persuasively that inventors and organizations employing them are purposeful, and in a wide range of cases an important objective is profit. Their essays provided strong support for the proposition that the allocation of inventive effort is influenced by perceptions of where technically successful inventions will find a strong demand, and also by considerations of technical feasibility and the likely cost and time of achieving an advance. Much of the work on technological advance by economists since that time has been based on, and provided more evidence supporting, this perspective.

Richard R. Nelson is the George Blumenthal Professor of International and Public Affairs Emeritus at Columbia University and Director of the Program on Science, Technology, and Global Development at the Columbia Earth Institute. 
However, the essays and discussion also display an uneasiness about treating invention as an activity in which the actors optimized in any nonsophistical sense of that term. The uncertainties involved in the process, the high failure rate, and the creativity often shown in both successes and failures, seemed to call for another way of characterizing their behavior. Also, while not discussed explicitly, recognition of the dynamics of competition in industries where innovation was important, and the continuing turnover of firms in such industries, clearly raised questions about the relevance of equilibrium concepts in analysis of technological advance. Several of the essays highlighted that a good share of the relevant activity needed to be understood as proceeding in contexts where profit was not the dominant objective. More generally, the participants at the conference recognized that inventing had properties that differed strongly from the standard productive activity depicted in the economics textbooks, and that an invention was not a standard commodity. A number of the participants clearly believed that there was a need for the development of theory tailored to the particularities of technological change.

As I suggested earlier, several of the essays and much of the discussion stressed the importance of uncertainty in the inventive process, and the fact that many efforts ended in failure. It was highlighted that, while individual inventors often had great confidence in their ideas, there generally were significant differences in how different inventors and firms laid their bets, and it was very difficult to predict in advance who would be the winners and losers. The idea that it was highly desirable to run parallel efforts was put forth in several of the papers, and several commentators observed that this is an important feature of market competition. I noted then that this certainly is not a feature of market competition highlighted in the standard economics text books.

There also was considerable discussion of the issue of how inventors were able to appropriate returns from their successful inventions. Several of the authors pointed out that inventions were new ways of doing things that not only were "nonrivalrous in use" but also often easily imitable, if they were not protected in some way. The threat of rapid imitation was flagged by Arrow and others as a deterrent to private inventing. However, it was also recognized that the total social gains from new technology were enhanced when the know-how went public, and that sooner or later most technology gets into the public domain. There clearly are some important issues here not treated or even recognized in standard microeconomic theory.

As I looked again at the essays, and tapped my memory of the conference discussion, it is interesting that explicit reference to Schumpeter is quite limited. Where there was such reference, it mostly was in discussion concerned with whether significant innovation in an industry required that the firms in it be large ones. However, as I noted previously, a Schumpeterian view 
that innovation is the principal means of competition in many industries is implicit in several of the papers. This perspective on the nature of competition diverges radically from the view in standard microeconomics.

In addition, there was widespread recognition that much more than the market system was involved in supporting and orienting inventive activity. It was proposed that in many sectors inventive activity drew heavily from science that was undertaken largely at universities. In addition to supporting much of the basic research done in the United States, government also played a major role in funding and directing applied research and development in several important fields. Thus it was apparent to many of the participants at the conference that effective analysis of technological advance would require a conceptual structure that encompassed a wider set of institutions and activities than were treated in the standard economic textbooks.

I also want to note here the apparent caution on the part of the scholars who were concerned with somehow measuring invention regarding the possibility of getting good quantitative measures. The various quantitative variables being discussed, and used in an exploratory way, generally were recognized as indicators of the phenomena being addressed, rather than being good measures of it. This was very much the case regarding the use of total factor productivity growth as a measure of the rate of technological advance, of patent numbers to indicate where and how much inventing was going on, and $\mathrm{R}$ and $\mathrm{D}$ numbers to "measure" inputs to inventing.

It is clear that many of the papers that attracted the most interest were detailed qualitative case studies, or analyses based on a collection of carefully detailed case studies. These were the studies that seemed to many of us to provide the most illumination regarding what inventive activity was all about.

While I did not recognize it at the time, with the advantage of hindsight one can see that this combination of features was going to make it difficult for empirically oriented study of technological advance to become fully conformable with the more general research orientation that the economics discipline increasingly was establishing as the norm. The theory of economic behavior that was coming to be treated as standard by the profession had apparent limitations as a way of orienting or interpreting research in this arena; thus, at least some of the research done by economists working in this field was going to proceed outside of this theoretical frame. The numbers that could be used in quantitative analysis had serious limitations as measures of the important variables and, therefore, much of our understanding of what is going on had to be qualitative, with numbers playing a useful role as indicators rather than accurate measures. However, since the time of the Rate and Direction Conference, the economics profession and the journals serving it have become less receptive to qualitative empirical studies. And the nature of the subject matter clearly called for an interdisciplin- 
ary approach to some of the key questions. Yet, economics as a general discipline was becoming increasingly separate from the other social and behavioral sciences.

In any case, the conference should be understood as part and parcel of a significant increase in interest by economists in technological advance that was occurring then in economics. Beginning around 1960, there was a burgeoning of research in this field.

That research has been quite varied in the questions explored, in the methodologies employed, and in the auspices of the research. Much of the research has been done by economists who have had their home in economics departments. A significant amount has been done by economists with appointments in business schools, some of that research on the topics economists in economics departments have been writing about, but some of it concerned with how firms develop the technological capabilities that they possess and the factors behind firm differences. Much of this research has been empirical and quantitative. Here I would like to specially recognize the work of the giants Jacob Schmookler, Edwin Mansfield, and Zvi Griliches. Nathan Rosenberg has done remarkable work on the history of technology. Some of the work has involved survey research. The NBER has been a sponsor and organizer of much of it. Much of it has been published in the regular economics journals.

However, a considerable amount of research in this broad field has been done by economists working in new research and teaching institutions, specifically oriented to the study of technological change, usually, but not always, oriented by a focus on issues of science and technology policy. The research done at the Science Policy Research Unit at the University of Sussex has made an especially important contribution to our understanding of how technological advance occurs. I note that these institutions, while providing a home for many economists studying technological advance, have had a definite interdisciplinary orientation. New journals like Research Policy, and The Journal of Evolutionary Economics, and Industrial and Corporate Change, have grown up around this intellectual community. Here I would like to specially recognize Keith Pavitt and Christopher Freeman as making enormous contributions to our understanding.

What are the major understandings that, as a result of this research, we now have that were not available to the scholars who participated in the Conference on the Rate and Direction? The discussion that follows obviously reflects my own judgments regarding what is important.

First of all, some of the arguments that might have been controversial at the time of the conference have been amply firmed up. There is no informed arguing now against the proposition that technological advance is the principal source of long-run productivity growth. We also now have much stronger evidence that, with few exceptions, industries where measured productivity growth and technological advance are great are characterized by high 
$\mathrm{R}$ and $\mathrm{D}$ intensity, or high $\mathrm{R}$ and $\mathrm{D}$ intensity of some of their upstream supplying industries, or both. The important influence of perceptions of profit opportunities in motivating and orienting inventive effort also has been amply confirmed.

But second, we now are much more conscious that there are very great differences across industries in their rates of technological advance. While this cross industry variability clearly is related to differences in R and D intensity, scholars are still struggling with the reason for these differences. My belief is that one important factor is differences in the strength of the underlying sciences on which industrial $\mathrm{R}$ and $\mathrm{D}$ draws in different industries.

Third, it is now much better understood that much of scientific research is in fields, like electrical engineering, computer science, and oncology, where practical problems and objectives play a nontrivial role in orienting effort. That is, different fields of science are specifically oriented to helping the advance of different technologies. We have come a long way from earlier beliefs, implicit in a number of the old Rate and Direction Conference essays, that the technological payoffs from basic research are largely a matter of serendipity. On the other hand, the uncertainties about the particular applications of new scientific knowledge, which was a matter stressed by several authors at that conference, have been amply confirmed.

Fourth, our understanding has improved greatly regarding the means by which inventors and firms appropriate returns from the new products and processes they create. It now is recognized much more clearly than it was at the time of the conference that patents are only one of the means, and that they play a major role in only a few technologies. Many inventions are much more costly and time consuming to imitate than economists earlier believed, and in many technologies the advantage of a head start, particularly if complemented by rapid subsequent improvement of the initial invention, is the principal source of return to inventing and R and D. We also know now that the principal means of appropriation differ across technologies and industries.

Fifth, a lot has been learned about Schumpeterian competition in industries where innovation is important, and about the dynamics of industrial structure under these conditions. The old argument about whether large firms with considerable market power were necessary for there to be significant innovation in an industry has more or less been replaced by an understanding of the differences in the roles played by new firms and established firms at different times in the history of a technology. A significant body of empirical research and modeling of industrial dynamics has been structured by the conception of a technology life cycle. Differences in industry structure associated with this and other factors have been more clearly recognized.

I note that several of these understandings highlight major differences across technologies and industries. This suggests strongly that it is a mis- 
take to argue in general about things like the role of university research, the importance of patents, or the importance of new firms in the innovation process, because these variables differ significantly across fields and economic sectors. I believe that many in the economics community have been slow in recognizing this.

I turn now to two matters that I and my working colleagues think we have learned, but are certainly controversial. First of all, a significant number of economists and other empirically oriented scholars of technological advance have come to propose that the process should be understood as evolutionary. The uncertainty involved in inventive activity leads to a diversity of efforts going on at any time to advance a technology, that are in competition with each other and with established technology. The winners and losers are determined to a considerable degree through actual comparison in use. And the results of today's competition and what has been learned today provide the context for the continuation of the competition tomorrow. This broad theoretical frame has provided the basis for a considerable amount of modeling, and also the orientation for a wide range of empirical research on technological change.

Second, a number of economists studying the subject empirically have come to the judgment that it is not helpful to view the institutional structure supporting innovation as essentially market organization, with nonmarket elements including public programs coming into the picture when markets fail, which is a point of view implicit in much of the main line economic writing. A considerable amount has been learned about the roles of nonmarket actors, particularly universities, since the days of the Conference on the Rate and Direction. For many scholars that have done that work it seems bizarre to propose that universities do what they do because of market failure. We also know much more now about the government programs, including programs of $\mathrm{R}$ and $\mathrm{D}$ support, that are important in many economic sectors, and many of these too, like those involved in defense contracting, seem not to be adequately rationalized in terms of responses to market failure. Several economists have developed the concept of an "innovation system" to characterize the range of different actors involved in the advancement of technology and the different roles they play.

These propositions about how technology advances and the range of actors involved in the process clearly are very different from the picture presented in today's standard economics textbooks (for example, in their treatment of growth theory). The divergence here testifies to the fact that the intellectual tensions I proposed were visible at the conference fifty years ago are very much evident today.

In any case, I suspect that while many of the readers of this essay are familiar with a number of the propositions I have just put forth, few are familiar with all. That is because different ones stem from the research of different groups of scholars, and unfortunately there is little cross-group 
communication. There are, first of all, economists relatively closely connected with the main line of the discipline. The NBER affiliates working on technological change are mostly in this camp. Economic historians in economics departments have also made significant contributions, but lately this group has been dwindling. There are, second, economists affiliated with research institutes dedicated to the study of issues of science and technology policy and of technological advance more broadly, and taking a transdisciplinary approach to the subject. Here, as I noted earlier, the research done by scholars at SPRU has been particularly important, but in recent years a number of other such institutions have become important loci of research.

In my view, while there is some overlap, for some time economists working in this area have been divided into two roughly separate camps each associated with different ways of dealing with the tensions that I suggested were visible at the Conference on the Rate and Direction. Economists in the first camp have stayed mainly within the confines of the discipline. They have accommodated to the tensions largely by being quantitative and empirical, and while urging caution about their numbers have tended to shun doing detailed qualitative case studies. They have been commonsensical in the theory they use and articulate in their work, while shying away from saying explicitly that the microeconomic theory of the textbooks does not work very well with the subject matter they are addressing.

Economists in the second camp have embraced the need to do detailed qualitative research and see quantitative data in the light of more qualitative understanding. They also have been more vocal in pointing out the inadequacies of standard microeconomics as a frame for understanding what is going on, and more active in entertaining and developing theory they think better suited to the subject matter. They have been active in developing a theory of the firm that is oriented to dynamic capabilities, and a neo-Schumpeterian theory of competition in industries where innovation is important that generates industrial dynamics. The development of evolutionary theory has largely been within this camp. They are comfortable with concepts like that of an innovation system that aims to encompass nonmarket as well as market actors in the process of technological advance.

Some economists have been able to bridge the divide, and act and think as members of both camps. But the divide clearly is there. Since the participants and presentations at the 2010 conference were largely those of the first camp, there was little opportunity for cross-group communication. However, we scholars of technological advance would benefit from more of it. 